\title{
Editorial
}

\section{O tempo das revistas}

\section{Editorial}

\section{The Time of the Journals}

Ana Paula Sampaio CALDEIRA http://orcid.org/0000-0001-8313-1062 Editora Chefe de Varia Historia Universidade Federal de Minas Gerais Av. Antônio Carlos 6627, Belo Horizonte, MG, 31.270-901, Brasil anapaula.sampaiocaldeira@gmail.com

"Publiquemos uma revista". É com esta frase que Beatriz Sarlo inicia seu conhecido ensaio Intelectuales y revistas: razones de una práctica, texto curto, mas muito instigante pelas questões teóricas trazidas para o estudo de um tipo específico de revistas: aquelas publicadas por intelectuais. Como lembra Sarlo, a frase "publiquemos uma revista" certamente foi pronunciada centenas de vezes por diversos intelectuais latino-americanos diante de seus pares, pautando a necessidade de um novo espaço de discussão e indicando o interesse de intervenção nos debates de seu tempo. Isso porque as revistas atuam de maneira diferente dos livros, estando inseridas em outra temporalidade. Os livros têm o médio e o longo prazo como seu tempo, são escritos muitas vezes para serem reconhecidos no futuro e adquirem mesmo certo ar de nobreza quando envelhecem. As revistas partilham de uma lógica diferente: fixam-se no presente, debatem os problemas de sua época, e perdem sua "aura" quando o presente se converte em passado. Por isso, "não há nada mais velho do que uma revista velha”! (Sarlo, 1992, p.9-10). 
Beatriz Sarlo certamente trata deste objeto, as revistas intelectuais, com conhecimento de causa, tanto em termos teóricos quanto práticos. Afinal de contas, como ressaltou Patrícia Artundo, na trajetória intelectual de Sarlo, ela não só fez desse tipo de periódico seu objeto de reflexão em diversos momentos, como esteve também na direção de uma revista, a Punto de Vista, durante longos anos (Artundo, 2010, p.11). Ou seja, Sarlo falava com muita propriedade quando apontava para a necessidade de pensar as revistas como projetos coletivos e como fontes privilegiadas para uma história intelectual, pois percebia o quanto esses projetos editoriais abrem espaço para pensar os agentes neles envolvidos e as relações que esses agentes mantêm entre si; as instituições às quais estão vinculados; os embates intelectuais e as correlações de força existentes em um campo da cultura; e também as relações que os periódicos constituem com seus públicos (Sarlo, 1992, p.16).

Em se tratando especificamente das revistas de história, alguns trabalhos têm apontado o quanto elas são materiais interessantes para os estudos na área da História da Historiografia. Como exemplo nesse sentido, ressalta-se o livro recentemente publicado e organizado por Julio Bentivoglio e Cristiano Alencar Arrais. Reunindo textos sobre periódicos que circulavam em diferentes espaços e em períodos distintos, o livro, numa perspectiva geral, aponta para o quanto o estudo das revistas de história pode ser interessante para o entendimento das mudanças no campo historiográfico (Bentivoglio, 2017, p.9). Por meio delas, é possível acompanhar o processo de profissionalização da disciplina, mas, igualmente, a análise desses materiais é também uma boa porta de entrada para os estudos das práticas acadêmicas e historiográficas (inclusive naquilo que as revistas mostram e escondem: os textos publicados e não publicados, as divergências historiográficas, as formas de financiamento das publicações, a constituição de alguns autores como referência, etc). Trabalhos que tomam como base as revistas de história têm se fortalecido no Brasil, mas parece que ainda são poucos os estudos sobre as produções periódicas mais recentes numa perspectiva própria à uma abordagem historiográfica. Isto é, análises que pretendam, por meio do estudo de revistas que nasceram há 30, 20 ou 
10 anos, acompanhar o movimento de estruturação da nossa disciplina, a formação de novas áreas de estudo, a especialização do historiador, o processo ainda em curso de profissionalização dos próprios periódicos, dentre muitas outras questões.

Apropriando-nos da ideia de Beatriz Sarlo de que não há nada mais velho do que uma revista velha, podemos imaginar o quanto os "velhos" primeiros exemplares de periódicos como a Varia Historia - e de muitas outras revistas importantes da área - poderiam nos ajudar a entender os debates travados há não muitas décadas em nossa área e a compreender o papel que esses periódicos desempenharam nestes debates. O estudo dessas publicações surgidas a partir das décadas de 1970/80, por exemplo, talvez tenha muito a nos dizer sobre a estruturação dos programas de pós-graduação e das instituições às quais as revistas estão vinculadas, sobre o processo de internacionalização de nossos ambientes universitários, acerca da circulação desse conhecimento acadêmico (em especial com a disponibilização online e gratuita de várias de nossas revistas), e também a respeito das demandas de produção e de publicação que incidem no trabalho do pesquisador/ professor universitário e cada vez mais entre os estudantes de pós-graduação.

O dossiê deste número de Varia Historia talvez seja um bom exemplo de que o tempo das revistas é o presente, em especial, pela atualidade da questão trazida pelos organizadores, os professores Georg Fischer (Aarhus Universtity) e Antoine Acker (University of Zurich). O dossiê "Historicizing Brazil's Great Acceleration" pretende discutir como escrever a história da chamada "grande aceleração" (este momento inédito de exploração dos recursos naturais a partir dos anos 1950), tomando o Brasil como estudo de caso. Questão urgente e necessária, debatida aqui por um conjunto de jovens pesquisadores, que atuam, estudam ou desenvolvem pesquisas em diferentes instituições nacionais e estrangeiras. Se a atualidade da questão é algo a ser ressaltado, outro aspecto que também vale a pena mencionar é o tipo de abordagem proposta, pois, embora os textos tenham como espaço privilegiado de análise o Brasil, eles ultrapassam as questões locais, já que a perspectiva é pensar os efeitos da grande aceleração no país, ressaltando como a sociedade 
brasileira enfrentou e viveu um fenômeno global. Aponta, portanto, para o diálogo estabelecido entre a pesquisa histórica produzida dentro e fora do país. Mais do que isso, lembrando que há pouco tempo a região de Mariana viveu um desastre ambiental que trouxe trágicas consequências para o ecossistema e para a vida de centenas de pessoas (e cujos culpados não foram devidamente responsabilizados pelos seus atos), esse episódio e tantas outras situações absolutamente preocupantes que temos vivido no Brasil nos instigam a pensar o quanto o conhecimento histórico pode contribuir para o entendimento das relações estabelecidas entre política, ciência, questões econômicas e meio-ambiente em nosso país.

\section{Agradecimentos}

Revistas são sempre projetos coletivos. Portanto, aproveito a oportunidade para agradecer a Anny Jackeline Torres da Silveira, Regina Horta Duarte e Douglas Attila Marcelino pelo diálogo e pela ajuda cotidiana. E agradeço também a Georg Fischer e Antoine Acker, pelo empenho no trabalho de construção do dossiê.

\section{REFERÊNCIAS}

ARTUNDO, Patrícia. Reflexiones en torno a un nuevo objeto de estudio: las revistas. Actas del IX Congreso Argentino de Hispanistas, La Plata, 27 a 30 abr., 2010.

BENTIVOGLIO, Julio. Revistas de história: objeto privilegiado para se estudar a história da historiografia? In: ARRAIS, Cristiano Alencar; BENTIVOGLIO, Julio (org). As Revistas de História e as Dinâmicas do Campo Historiográfico. Serra: Milfontes, 2017. p.7-30.

SARLO, Beatriz. Intelectuales y revistas: razones de una práctica. In: América: Cahiers du CRICCAL, n. 9-10, p. 9-16, 1992. 